\title{
Locating air quality monitoring stations utilizing computational fluid dynamics
}

Martin Jaeger, Desmond Adair, Meruyert Zhunussova

- School of Engineering

\begin{abstract}
With the advancement of high-resolution Computational Fluid Dynamics (CFD), measurements of variables related to the urban environment, such as air quality, can be optimized. Regarding smart solutions for the future cities, CFD allows for the optimizing of location for instrumentation to monitor air quality in order to facilitate optimized measures to counteract any potential detrimental effect on the local populations' health, at relatively low cost. To illustrate the power and efficiency of CFD this paper reports on a study in Kuwait of the dispersion of $\mathrm{CO} 2$ gas. Based on the case of dispersion of $\mathrm{CO} 2$ emanating from traffic in a busy street and in the vicinity of a complex configuration of buildings located in Salmiya, Kuwait City, the suggested location for installing air quality monitoring instrumentation has been identified for two situations: before and after adding a new building. Before adding the new building, the highest $\mathrm{CO} 2$ concentration was found in the immediate proximity of the residential buildings some $200 \mathrm{~m}$ South-East of the main street. After adding the new building, the highest $\mathrm{CO} 2$ concentration was found on the windward side of the new building immediately next to the main street. The new configuration of buildings suggests a new location for any air quality monitoring instrumentation in order to measure the highest concentration of air pollution.
\end{abstract}

Original language

Title of host publication

Publisher

ISBN (Electronic)

State

Event
English

2016 Smart Solutions for Future Cities

Institute of Electrical and Electronics Engineers Inc.

9781467388351

Published - Apr 52016

Smart Solutions for Future Cities 2016 - Kuwait, Kuwait

Jaeger, M., Adair, D., \& Zhunussova, M. (2016). Locating air quality monitoring stations utilizing computational fluid dynamics. In 2016 Smart Solutions for Future Cities. [7447880] Institute of Electrical and Electronics Engineers Inc.. DOI: 10.1109/SSFC.2016.7447880 